\title{
Study on confined end-regions of RC walls under monotonic and cyclic loadings
}

\author{
Rafik Taleb ${ }^{1, *}$ and Susumu Kono $^{2}$ \\ ${ }^{1}$ Department of Civil Engineering, University of Blida 1, Blida, Algeria \\ ${ }^{2}$ Institute of Innovative Research, Tokyo Institute of Technology, Yokohama, Japan
}

\begin{abstract}
A study was conducted to clarify the influence of reinforcement detailing, slenderness and loading type on the capacity, damages and failure modes of confined boundary regions of reinforced concrete $(R C)$ cantilever walls. It was found that the tensile strain prior to compressive strain affected the performance of thin wall boundaries and may lead to different failure modes compared to compression load only. It was also found that dense transverse reinforcement detailing in thin confined boundaries did not improve their performance. Some design and detailing practices were evaluated to determine their accuracy in preventing global buckling and bar buckling under extreme lateral loading. Numerical model that take into account reinforcing bar buckling was proposed to simulate the behaviour of specimens tested under monotonic condition. The model could simulate the observed response with good accuracy.
\end{abstract}

\section{Introduction}

Following the 2010 Chile and the 2012 New Zealand earthquakes, observed damages in $\mathrm{RC}$ wall buildings raised concern about the seismic performance of rectangular RC walls. In these earthquakes, severe damage happened to concrete walls in numerous walled buildings leading to partial or total collapse. Structural wall damages of boundary regions included spalling and crushing of concrete, often spread over the entire wall width, longitudinal reinforcement in those regions fractured under tension or buckled under compression, and apparent out-of-plan wall buckling was also observed in some damaged buildings $[1,2,3]$. It was reported that lack of adequate confinement and detailing in boundary regions was one of the main causes of those damages. These observations raise questions about the mechanisms that lead to reinforcing bars buckling, concrete crushing, and global wall buckling, as well as the quantity and configuration of transverse reinforcement at wall boundaries required to ensure good performance.

This study is a contribution to clarify the influence of reinforcement detailing, slenderness and loading type on the capacity, damages and failure modes of confined boundary regions of RC rectangular walls. One of the objectives of this study is to assess whether or not out-ofplan buckling and buckling of vertical reinforcement could be expected at the boundaries of concrete walls, and to explore the relationship between the phenomena of concrete crushing and reinforcing bar buckling. It is also important to predict the influence of ultimate failure mode on ultimate drift capacity of RC walls and build numerical model able to take into account these damage situations.

\section{Experimental Program}

An experimental program was conducted in order to bring insight on the seismic performance of confined end regions of RC rectangular walls. The behaviour of boundary regions in a ductile $\mathrm{RC}$ wall subjected to lateral loading was studied by isolating the boundary regions of the wall as an axially loaded RC column. Although the approach does not account for the strain gradient expected across the section, the idealization is useful in providing an understanding of the mechanism involved during lateral loading of the $\mathrm{RC}$ wall. The objective was to investigate the influence of longitudinal and transverse reinforcement amount, slenderness and load type (Monotonic and cyclic) on their capacity, damage process and failure modes.

\subsection{Description of the test specimens}

Table 1 shows cross-sectional configurations and reinforcement layouts of the tested elements. Eight rectangular elements with two different sectional dimensions (B-type and C-type) having approximately similar cross-sectional area were constructed and tested. The element specimens were built without considering cover concrete so that the intermediate damage state due to spalling of cover concrete could be omitted, since the objective was to assess ultimate behaviour and failure

\footnotetext{
* Corresponding author: rafik.taleb.dz@gmail.com
} 
modes. The cross sections were $112 \times 242 \mathrm{~mm}^{2}$ and $72 \times 367$ $\mathrm{mm}^{2}$ for B-type and C-type elements, respectively, representing two levels of slenderness. The dimensions are measured from centreline to centreline of extreme transverse reinforcing bars. The shorter side length of the section corresponds to the wall thickness. For each sectional type, two levels of transverse reinforcement were set. The four configurations were replicated in order that each configuration is tested under monotonic compression load and cyclic reversal load. The latter character in the specimens label stand for loading type: $\mathrm{M}$ for monotonic and $\mathrm{C}$ for cyclic. Table 2 shows the amounts of longitudinal and transversal reinforcement as well as loading type for each element specimen. D4 deformed reinforcing bars were used for transverse reinforcement for lightly confined specimens with $80 \mathrm{~mm}$ and $70 \mathrm{~mm}$ spacing for $5 \mathrm{~B}$ and $1 \mathrm{C}$ configurations, respectively, and D6 deformed bars for densely confined specimens with $80 \mathrm{~mm}$ and $40 \mathrm{~mm}$ spacing for $6 \mathrm{~B}$ and $3 \mathrm{C}$ configurations, respectively. $5 \mathrm{~B}$ and $1 \mathrm{C}$ as well as $6 \mathrm{~B}$ and $3 \mathrm{C}$ elements were designed to have approximately similar transverse reinforcement ratio. All transverse reinforcement had 135-degrees hoops. D16 and D10 reinforcing bars were used for longitudinal reinforcement for B-type and C-type elements, respectively. Fig. 1 shows vertical reinforcement layout of $6 \mathrm{~B}$ configuration. Longitudinal reinforcing bars of elements were bent 180 degrees at their ends and hanged to a D25 deformed reinforcing bars in the upper and lower stub to ensure fixity. D25 bars were also used as longitudinal reinforcement for lower and upper stub with D10 as transverse reinforcement. The tested elements had $600 \mathrm{~mm}$ height with fix-ended at both ends. This height represents the lower portion of the confined boundary in a wall where likely compressive failure may occur.

Table 1. Cross-sections and reinforcement details

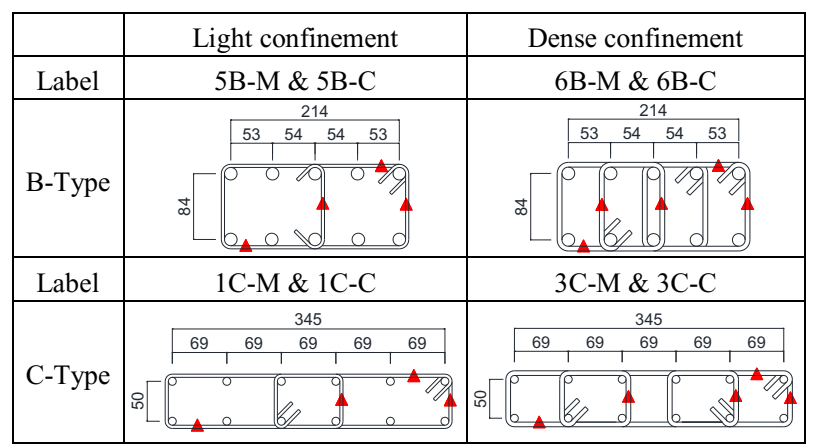

Table 2. Reinforcement amount and loading type

\begin{tabular}{|c|c|c|c|}
\hline Specimen & $\begin{array}{l}\text { Longitudinal } \\
\text { Reinf. }\end{array}$ & $\begin{array}{l}\text { Transverse } \\
\text { Reinf. }\end{array}$ & Loading type \\
\hline $5 \mathrm{~B}-\mathrm{M}$ & \multirow{4}{*}{$\begin{array}{c}10-D 16 \\
\left(p_{g}=7.33 \%\right)\end{array}$} & \multirow{2}{*}{$\begin{array}{c}3-\mathrm{D} 4 @ 80 \\
\left(\mathrm{p}_{\mathrm{w}}=0.22 \%\right)\end{array}$} & Monotonic \\
\hline 5B-C & & & Cyclic \\
\hline 6B-M & & \multirow{2}{*}{$\begin{array}{c}6-D 6 @ 60 \\
\left(\mathrm{p}_{\mathrm{w}}=1.27 \%\right) \\
\end{array}$} & Monotonic \\
\hline 6B-C & & & Cyclic \\
\hline $1 \mathrm{C}-\mathrm{M}$ & \multirow{4}{*}{$\begin{array}{c}12-\mathrm{D} 10 \\
\left(\mathrm{p}_{\mathrm{g}}=3.24 \%\right)\end{array}$} & \multirow{2}{*}{$\begin{array}{c}4-\mathrm{D} 4 @ 70 \\
\left(\mathrm{p}_{\mathrm{w}}=0.22 \%\right)\end{array}$} & Monotonic \\
\hline $1 \mathrm{C}-\mathrm{C}$ & & & Cyclic \\
\hline 3C-M & & \multirow{2}{*}{$\begin{array}{c}\text { 6-D6@40 } \\
\left(\mathrm{p}_{\mathrm{w}}=1.29 \%\right)\end{array}$} & Monotonic \\
\hline $3 \mathrm{C}-\mathrm{C}$ & & & Cyclic \\
\hline
\end{tabular}

Observations from previous experimental studies indicate that the compressive failure region is quite limited within a height of about 2.5 times the wall thickness [5]. The elements were casted in two stages: first the lower stub and then the element and the upper stub as one part with intentionally roughened surface created at lower stub-element interface to insure adherence. Table 3 and Table 4 show measured material properties for reinforcing bars and concrete, respectively. A concrete mix with $13 \mathrm{~mm}$ of maximum aggregate size and $12 \mathrm{~cm}$ for slump test were used.

Table 3. Concrete mechanical properties

\begin{tabular}{|c|c|c|c|}
\hline $\begin{array}{c}\text { Compressive } \\
\text { strength } \\
(\mathrm{MPa})\end{array}$ & $\begin{array}{c}\text { Strain at } \\
\text { peak } \\
(\%)\end{array}$ & $\begin{array}{c}\text { Young's } \\
\text { modulus } \\
(\mathrm{GPa})\end{array}$ & $\begin{array}{c}\text { Splitting } \\
\text { strength } \\
(\mathrm{MPa})\end{array}$ \\
\hline 24.5 & 0.18 & 26.3 & 2.3 \\
\hline
\end{tabular}

Table 4. Reinforcing bars mechanical properties

\begin{tabular}{|c|c|c|c|}
\hline bars & $\begin{array}{c}\text { Yield } \\
\text { strength } \\
(\mathrm{MPa})\end{array}$ & $\begin{array}{c}\text { Ultimate } \\
\text { strength } \\
(\mathrm{MPa})\end{array}$ & $\begin{array}{c}\text { Young's } \\
\text { modulus } \\
(\mathrm{GPa})\end{array}$ \\
\hline D4 & 363 & 532 & $/$ \\
\hline D6 & 365 & 516 & 192 \\
\hline $\mathrm{D} 10$ & 347 & 484 & 190 \\
\hline $\mathrm{D} 16$ & 325 & 462 & 188 \\
\hline $\mathrm{D} 25$ & 381 & 567 & 192 \\
\hline
\end{tabular}
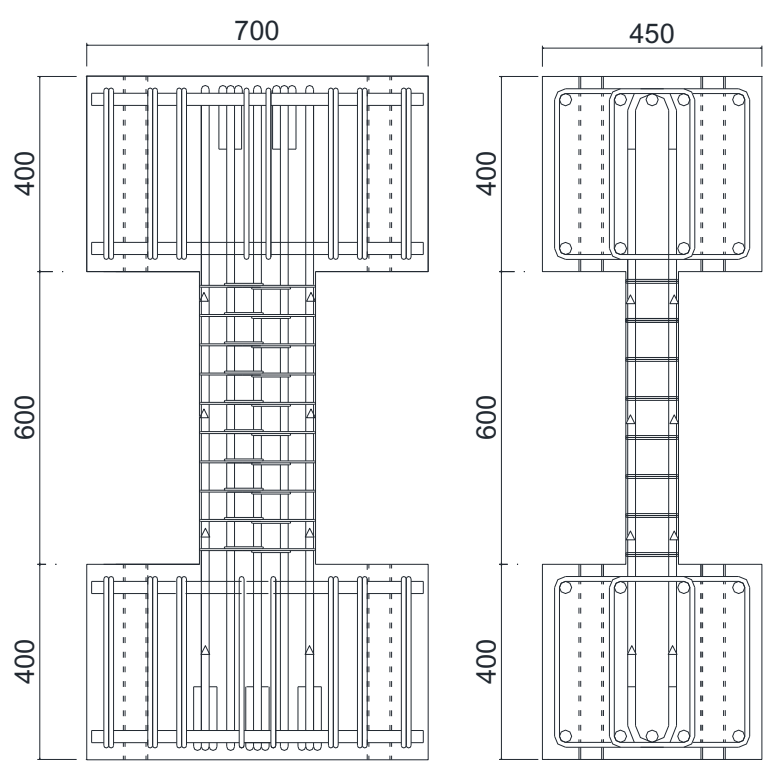

Fig. 1. Dimensions and vertical reinforcement layout for 6BM/6B-C elements front view (left) side view (right).

\subsection{Loading method and measurement}

A universal testing machine was used to apply vertical load on the upper stub under the condition of uniaxial tension and compression (Fig. 2). For monotonic tests, the axial compression load was applied gradually until failure, while for cyclic tests axial loading history was determined based on the average strain at the lower part of previously tested RC structural walls [6]. A ratio of tensile-to-compressive strain of 5 was used to set the 
loading protocol. Thus, the loading cycle consisted of an initial half cycle of axial tensile strain followed by a compression half cycle with a nominal target compressive strain $1 / 5$ of the axial tensile strain, unless the compression cycle was limited by the capacity of the loading machine which was $1500 \mathrm{kN}$. The test was considered complete when the resistance of the specimen decreased significantly, and the specimen exhibited signs of instability. Thus, two cycles of loading were applied that correspond to yielding strain followed by tensile strains of $0.5 \%, 1 \%, 1.5 \% 2 \%, 3 \%$ and $4 \%$. A load cycle is considered to be stable if the target compressive strain can be reached in two successive cycles without excessive damage. Figure 3 shows test setup and loading protocol. The specimens were tested at low rate of loading to ensure that no strain rate effects were introduced during the test. Displacement transducers were mounted to both ends of the longer side length of the section, which was divided into three measuring zones $\mathrm{Z} 1, \mathrm{Z} 2$ and $\mathrm{Z} 3$. These zones were set at intervals of $0 \sim 50 \mathrm{~mm}$ for $Z 1$ at the bottom part of the element, $50 \sim 550 \mathrm{~mm}$ for $\mathrm{Z} 2$ at the middle, and $550 \sim 600 \mathrm{~mm}$ for $\mathrm{Z} 3$ at the top part for B-type elements, and at intervals of $0 \sim 40 \mathrm{~mm}$ (Z1), 40 560mm (Z2) and $560 \sim 600 \mathrm{~mm}$ (Z3) for C-type elements. Two displacement transducers were also installed between upper and lower stub at both sides to check any possible inclination during test. The nominal axial strain was defined experimentally as the strain corresponding to average displacement at both ends of the element over the total height.

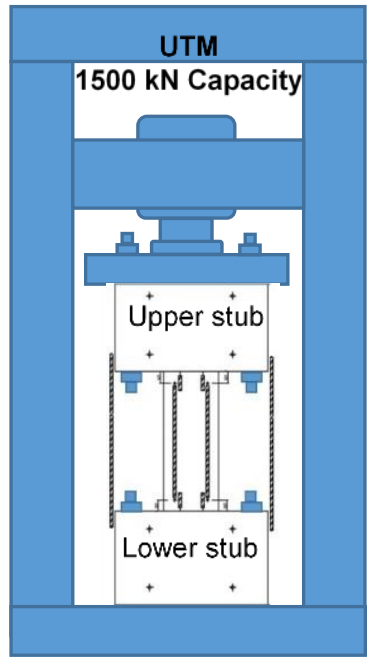

Fig. 2. Test setup and transducers layout.

\section{Damage process and failure modes}

For each configuration, damage situation is presented for monotonic and cyclic loading conditions. All elements tested under monotonic compression exhibited a stable behaviour without apparent damages until peak load. Following peak load point, different damage evolutions and failures were observed. For cyclically tested elements, horizontal cracks appeared at top and bottom element-stub interface and uniformly at transverse reinforcement planes when loading in tension, indicating that these cracks were initiated by the transverse reinforcement. Further tension loading led to widely opened horizontal cracks. Damage evolution and failure modes differences are described in the following.

\subsection{B-type elements}

Fig. 3 shows the final damage situation for B-type elements. For 5B-C element, horizontal cracks opened widely and new horizontal cracks formed at mid-spacing between transverse reinforcement at further tensile strains. At final stage, buckling of multiple longitudinal reinforcing bars happened simultaneously at mid-height region over three and four spacing of transverse reinforcement triggered by the spalling of surface concrete due to larger longitudinal bars diameter (D16).
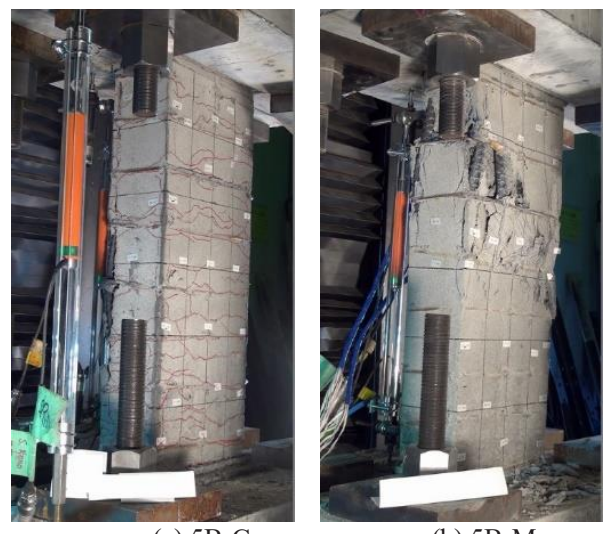

(a) $5 \mathrm{~B}-\mathrm{C}$

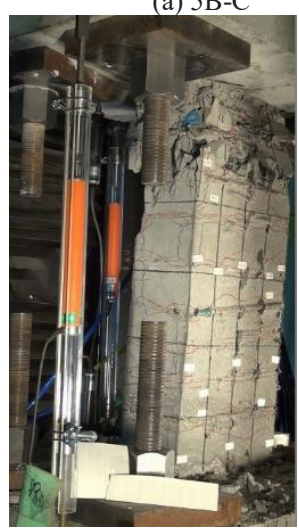

(c) $6 \mathrm{~B}-\mathrm{C}$

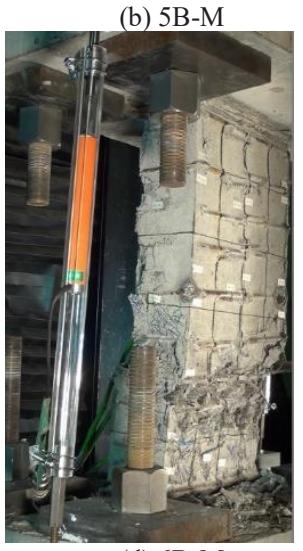

(d) $6 \mathrm{~B}-\mathrm{M}$

Fig. 3. Final damage situation for B-type elements.

The transverse reinforcement (D4@80) could not contribute effectively to retain longitudinal bars and preventing them from buckling over large buckling length even though ratios of hoop spacing to longitudinal bar diameter, $s / d_{b}=5$, is within the limit of the ACI 318 [7]. This suggest that anti-buckling detailing provisions should also be related to the ratio of longitudinal-totransverse bar diameters. Buckling of longitudinal reinforcement was followed by crushing of concrete in the buckling region. Buckling of unsupported intermediate bars was more pronounced compared to other bars. 5B-M element under monotonic loading reached maximum capacity without visible damage, followed by spalling of concrete and buckling of longitudinal reinforcement over two and three transverse reinforcement spacing similarly to $5 \mathrm{~B}-\mathrm{C}$ element. 
For 6B-C element, horizontal cracks appeared only at transverse reinforcement planes under tension loading and opened widely as tensile strains increased. At final loading stage, both $6 \mathrm{~B}-\mathrm{C}$ and $6 \mathrm{~B}-\mathrm{M}$ elements failed by crushing of compressive concrete followed by localized buckling of the damaged region, but no buckling of longitudinal reinforcement was observed. The damaged region was located at the lower portion of for $6 \mathrm{~B}-\mathrm{M}$ and at the top for $6 \mathrm{~B}-\mathrm{C}$.

\subsection{C-type elements}

Fig. 4 shows the final damage situation for C-type elements. For 1C-C and 1C-M elements, both elements failed by buckling of longitudinal reinforcement under compression. Buckling was observed over two and three transverse reinforcement spacing for $1 \mathrm{C}-\mathrm{M}$, while buckling length extended over more than four spacing due to pre-cracks induced by tensile strain. Pre-cracking condition facilitate the buckling of longitudinal reinforcement in addition the very thin concrete core. Similarly, to 5B elements, buckling of unsupported intermediate bars was more pronounced than other bars, suggesting that restraining unsupported intermediate bars in the confined boundary region should be considered, especially for slender walls.
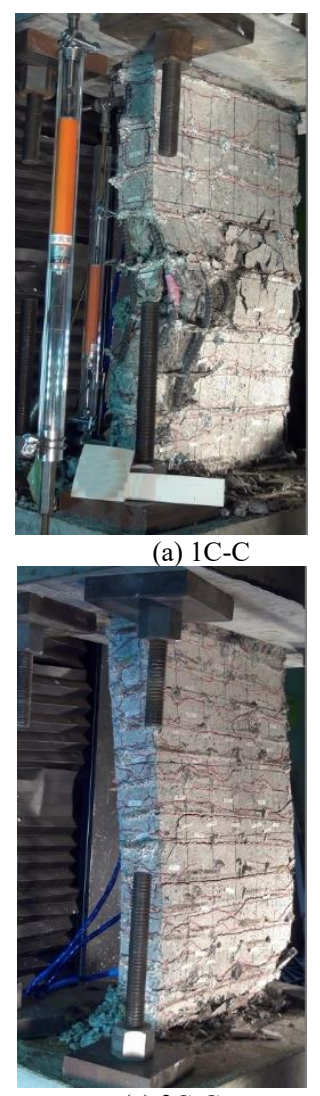

(c) $3 \mathrm{C}-\mathrm{C}$

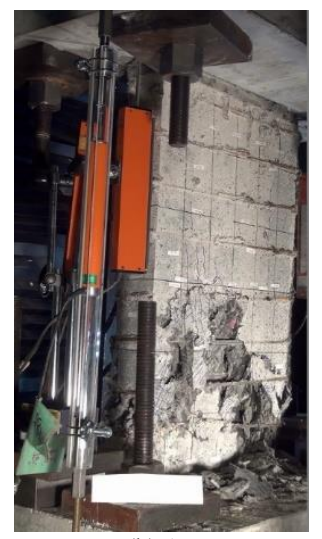

(b) 1C-M

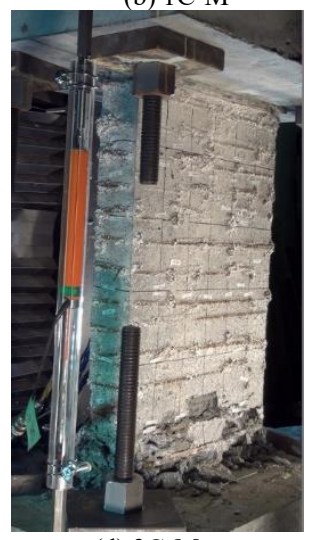

(d) $3 \mathrm{C}-\mathrm{M}$
Fig. 4. Final damage situation for C-type elements.

Final failure for 3C-M element was due to extensive crushing of compressive concrete at the bottom of element over a very limited height corresponding to approximately two transverse reinforcement spacing. Crushing of concrete for 3C-C element was also concentrated at the bottom within limited height, similarly to 3C-M. However, crushing of concrete in 3C-C was followed by global buckling of the element when unloading from the second cycle of $4 \%$ tensile strain indicating that global buckling was driven by prior induced large tensile strain which demonstrates the vulnerability of confined boundaries of slender walls to tensile strain excursions prior to compressive strain. Spread of concrete crushing was very limited in height compared to B-type elements. Globally, no difference of the failure modes was shown when comparing failures under monotonic and cyclic loading condition. Exception was noted for 3C configurations. 3C-M element failed due to extensive crushing of concrete, while $3 \mathrm{C}-\mathrm{C}$ element showed a limited concrete crushing region at the base followed by out-of-plan buckling. Prior crushing assisted the global buckling to happen over almost the total height of the element and resulted in a large out-of-plan displacement.

\section{Experimental load-strain relations}

Fig. 5 shows axial load versus axial nominal strain relationships for all specimens. Each plot in the figure represent response relations for both monotonic and cyclic loading. The upper and lower dashed lines indicate, respectively, the calculated loads corresponding to the yielding of longitudinal reinforcements and the compressive strength as sum of the concrete uniaxial compressive strength and compressive yield stress of longitudinal reinforcement. It should be noted that excessively large compressive strain for $6 \mathrm{~B}$ elements was due to a rotation of the elements prior to extensive crushing. Under low level of axial tensile strains for element tested under cyclic loading, a stable response was observed. However, increasing the tensile strain level led to different response. These differences and the comparison monotonic and cyclic loading response are summarized in the following.

It was noted that thin boundaries (C-Type) were not able to fully develop the compressive strength. This configuration could not provide sufficient confinement although the transverse reinforcement ration was high for $3 \mathrm{C}$ elements. The low confinement ratio and large difference between longitudinal-to-transverse bar diameters for $5 \mathrm{~B}$ configuration led also to a lower compressive capacity. However, comparison of load carrying capacity between monotonic and cyclic loadings showed no significant difference for all tested elements. Comparison between monotonic and cyclic response for elements with failure mode governed by buckling of longitudinal reinforcement (5B, and $1 \mathrm{C}$ configurations) showed that prior tensile strain effects considerably the load level at onset of bar buckling. Onset of bar buckling for elements tested under monotonic compression (5B-M and $1 \mathrm{C}-\mathrm{M}$ ) was noted around peak capacity point, followed by a rapid drop of the load carrying capacity.

This revealed that the failure of those elements was related to longitudinal bar buckling. Following bars buckling, the core concrete could not sustain the total axial load and crushed rapidly. Response curves of elements that failed by buckling of longitudinal bars 

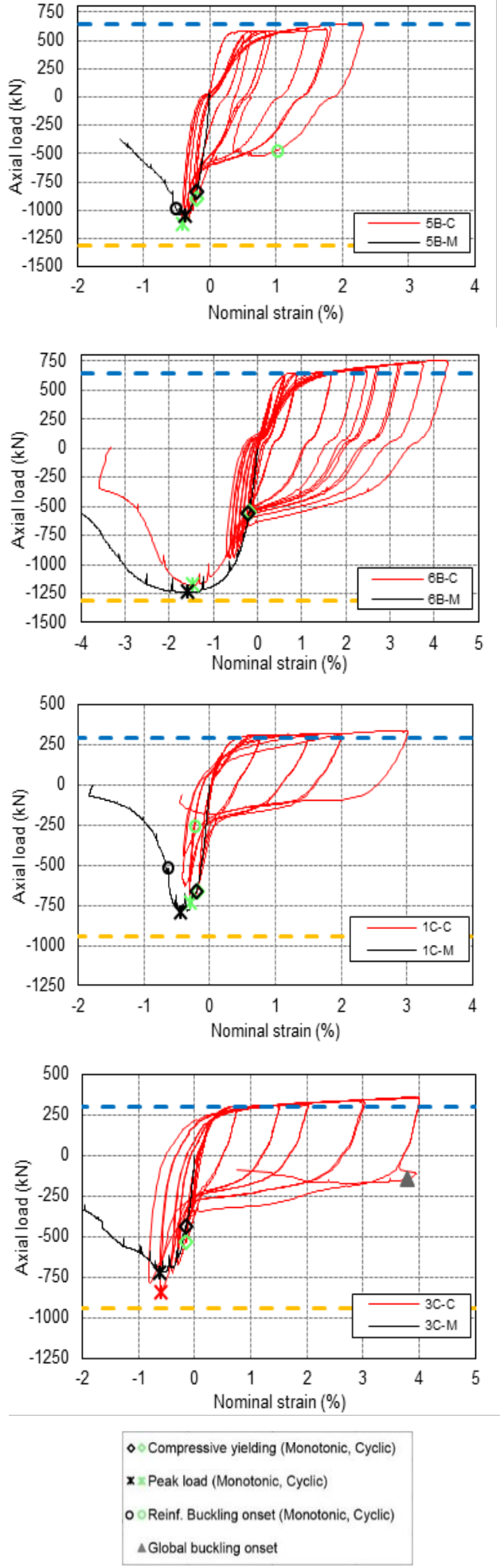

Fig. 5. Axial load-Nominal axial strain relationships

showed a quick decrease of axial load after the peak compressive load was reached. A sudden drop of the capacity was observed and manifested by the rapid concrete crushing at the region of reinforcement buckling. On the other hand, elements tested under cyclic loading (5B-C and $1 \mathrm{C}-\mathrm{C}$ ) showed onset of bar buckling at lower compressive load before cracks completely closed following unloading from peak tensile strain. Onset of bar buckling for 5B-C element was observed at approximately $-220 \mathrm{kN}$ that correspond to about $80 \%$ less than load level under monotonic compression. Onset of bar buckling happened after unloading from the first cycle of $2 \%$ tensile strain. Onset of bar buckling for $1 \mathrm{C}-\mathrm{C}$ element started when unloading from the second cycle of $1.5 \%$ tensile strain to the corresponding compressive strain, that is compressive strain corresponding to compressive peak load. The following cycle was marked by buckling of several longitudinal bars and capacity drop. This demonstrate vulnerability of slender element to bar buckling following even limited tensile strain excursions. Response curves of elements failed due to concrete crushing showed a smoother decrease of load carrying capacity compared to elements with failure mode started by longitudinal bar buckling.

Comparing densely and lightly confined specimens, it was shown that well confined specimens revealed capability to sustain larger tensile strain in a stable manner. However, dense transverse reinforcement detailing in thin elements added little to the compressive capacity. Comparison of compressive capacity between $1 \mathrm{C}$ and $3 \mathrm{C}$ configurations displayed similar capacity even though the transverse reinforcement ratio in $3 \mathrm{C}$ was set more than 5 times of that in $1 \mathrm{C}$. These observations suggest that it may not be even possible to provide enough confinement in thin sections by close transverse reinforcement spacing because the core concrete area is small, and the pattern of concrete crushing indicates that compression strain concentrates over a very short height. Comparing the two levels of slenderness (B-type and Ctype), it was shown that, for thin core concrete (C-Type elements), a stable compression zone could not be sustained and spread of concrete crushing by confined core concrete could not be ensured. For both configurations, undesired failure modes happened. Imposing a minimum wall thickness would be an alternative means to suppress failures due to global buckling and maintain a stable compression zone.

\section{Potential of undesirable failure modes}

\subsection{Lateral buckling instability}

Lateral instability related to global out-of-plan buckling may not be easily perceptible at the design level because their impact is difficult to quantify even with the current analysis capabilities. Tendency to buckle in RC walls depend primarily on the wall slenderness ratio and the maximum expected tensile strain in the boundary longitudinal reinforcement.

In $3 \mathrm{C}-\mathrm{C}$ element, wide cracks developed at transverse reinforcement planes as a results of a large yield excursion could not close prior to full development of maximum axial strength in the reversed direction due to residual tensile strain in the previously yielded longitudinal reinforcement. It was shown that damage situation of $3 \mathrm{C}$ $\mathrm{C}$ element caused a critical condition affecting the lateral stability. However, crushing of concrete at the base of $3 \mathrm{C}$ $\mathrm{C}$ prior to global buckling contributed in a large out-ofplan displacement when unloading from the second cycle of $4 \%$ tensile strain since it acted as pin joint. This reveals that both large axial strain prior to compressive strain and 
prior crushing affect the global buckling failure mode for slender walls. Imposing a minimum wall thickness or minimum thickness for confined boundaries would be an inevitable means to eliminate failures due to global buckling.

Based on buckling theory for prismatic sections under cyclic loading, a relation between the critical slenderness ratio for the wall boundary element and the maximum tensile strain prior to compressive load, $\varepsilon_{s m}$, was proposed by Parra and Moehle [8] given by:

$$
k h_{0} / b_{c r}=1 /\left(0.7 \sqrt{\varepsilon_{s m}-0.005}\right)
$$

where $b_{c r}$ is the critical wall boundary thickness, $h_{0}$ is the clear height, and $k$ is the effective height coefficient taken as 0.8 .

Fig. 6 compares between theoretical relation for wall instability given by Eq. (1) and elements test results. Considering failure mode due to crushing prior of global buckling of slender wall boundaries, the equation could well predict the potential of $3 \mathrm{C}-\mathrm{C}$ element for global buckling.

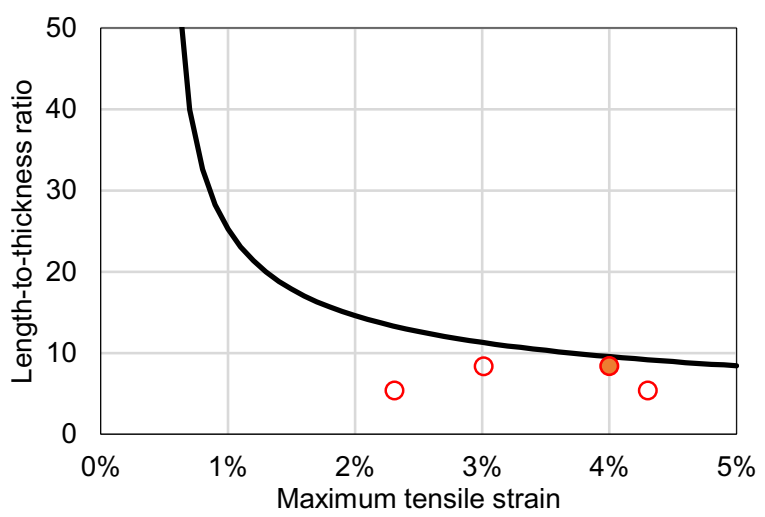

Fig. 6. Comparison with theoretical relation for global buckling.

\subsection{Reinforcing bar buckling}

Issues related to buckling of longitudinal reinforcing bars are usually addressed by limiting the ratio of transverse reinforcement spacing to longitudinal bar diameter, $s / d_{b}$. Large $s / d_{b}$ ratios may result in limited confinement of concrete, and leave longitudinal reinforcement more vulnerable to buckling instability. ACI 318, for example, limit the ratio of $s / d_{b}$ to 6 . However, it was shown for configuration $5 \mathrm{~B}$ The transverse reinforcement could not contribute effectively to retain longitudinal bars and preventing them from buckling over large buckling length even though ratios of hoop spacing to longitudinal bar diameter, $s / d_{b}=5$, is within the limit of the ACI 318. This damage situation is due to the large difference between longitudinal and transverse reinforcing bar diameters, suggesting that anti-buckling detailing provisions should also be related to the ratio of longitudinal-to-transverse bar diameters as an additional detailing requirement.

Rodriguez et al. [9] introduced a criterion to assess the onset of bar buckling. based on monotonic and cyclic tests on isolated reinforcing bars with various $s / d_{b}$ ratios. Tests indicated that bars subjected to cyclic loading were more susceptible to buckling failures than bars subjected to monotonic loading. A parameter, $\varepsilon p^{*}$, was introduced as an indicator of the onset of bar buckling. However, this approach is limited to $s / d_{b}$ ratio equal to 8 and does not take into account buckling susceptibility over multiple transverse reinforcement spacing and lead to large strain at the onset of bar buckling (Fig. 7).

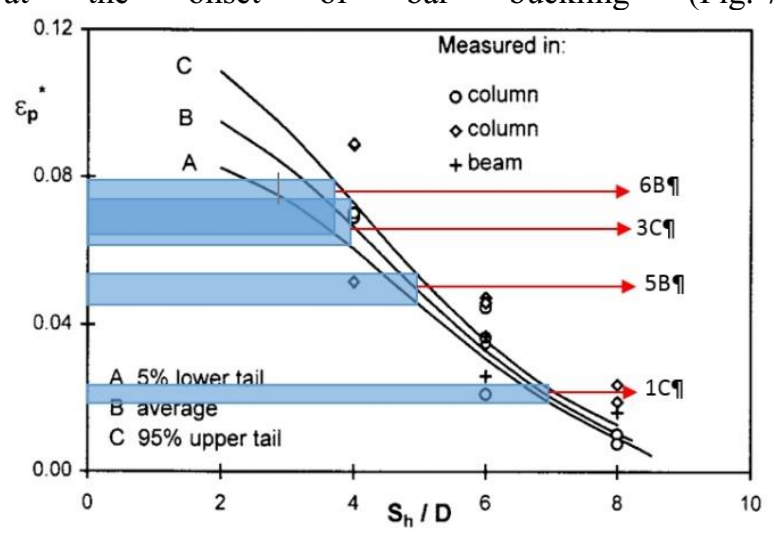

Fig. 7. Axial load-Nominal axial strain relationships.

\section{Prediction of load-strain relations}

In order to simulate the envelope curve of tested elements, a numerical model is proposed based on Sakino and Sun confined concrete model [10] with and without taking into account buckling of reinforcement. Mathematical expression for the stress-strain relation is defined as follow:

$$
\begin{gathered}
\frac{f_{c}}{f^{\prime}{ }_{c c}}=\frac{A X+(D-1) X^{2}}{1+(A-2) X+D X^{2}} \\
X=\varepsilon_{c} / \varepsilon_{c o} \\
A=E_{c} / E_{\mathrm{sec}} \\
E_{\mathrm{sec}}=f^{\prime}{ }_{c c} / \varepsilon_{c o}
\end{gathered}
$$

With $f_{c}$ and $\varepsilon_{c}$ are the stress and strain, respectively. $f^{\prime}{ }_{c c}$ and $\varepsilon_{c o}$ are the stress and strain at the peak, respectively, $E_{c}$ is the concrete Young's modulus, $E_{s e c}$ is the secant modulus at the peak point. Parameter $D$, governing the slope of descending branch, and stress and strain at the peak are given by:

$$
\begin{gathered}
D=1.5+0.017 f_{c}^{\prime}+0.33 \sqrt{(K-1) f^{\prime}{ }_{c}} \\
f^{\prime}{ }_{c c}=f^{\prime}{ }_{c}+11.5 \rho_{h} f_{h s} \frac{d^{\prime}}{C}\left(1-\frac{s}{2 d_{c}}\right) \\
\frac{\varepsilon_{c o}}{\varepsilon_{c}}= \begin{cases}1+4.7(K-1) & K \leq 1.5 \\
3.35+20(K-1.5) & K>1.5\end{cases}
\end{gathered}
$$

where $f_{c}^{\prime}$ strength of concrete cylinder in $\mathrm{MPa}, \rho_{h}$ volumetric ratio of hoops to the confined core measured centre-to-centre of perimeter hoop, $f_{h s}$ is the yield stress of hoops, $d^{\prime}$ 'is the nominal diameter of perimeter hoop, $C$ is centre-to-centre distance between longitudinal bars supported by perimeter hoops or intermediate hoops, $s$ is 
hoops spacing, $d_{c}$ is distance between the centroids of perimeter hoop, $\varepsilon_{0}$ is peak strain of unconfined concrete, and $K=f^{\prime}{ }_{c c} / f^{\prime}{ }_{c}$ is the strength enhancement coefficient of due to confinement.

For reinforcement, an elastic-perfectly plastic bilinear model was used for the case without buckling of reinforcement, while Dhakal and Maekawa model was used to take into account buckling of reinforcement [11, 12]. Dhakal and Maekawa propose that the buckling behaviour of reinforcement depends on the expression $L / D \sqrt{ } f y$, where $L$ is the buckling length, $D$ is the diameter of the longitudinal bar, and $f_{y}$ is the yield strength of the longitudinal bar. The stress-strain relation is defined as follow:

$$
\frac{\sigma_{s c}}{\sigma_{t}}=1-\left(1-\frac{f_{i}}{f_{i t}}\right)\left(\frac{\varepsilon_{s c}-\varepsilon_{y}}{\varepsilon_{i}-\varepsilon_{y}}\right) \quad \text { for } \varepsilon_{y}<\varepsilon_{s c} \leq \varepsilon_{i}
$$

and

$$
\sigma_{s c}=f_{i}-0.02 E_{s}\left(\varepsilon_{\mathrm{sc}}-\varepsilon_{\mathrm{i}}\right) ; \sigma_{s c} \geq 0.2 f_{y} \text { for } \varepsilon_{y}<\varepsilon_{s c} \leq \varepsilon_{i}
$$

with,

$$
\begin{gathered}
\frac{\varepsilon_{i}}{\varepsilon_{y}}=55-2.3 \sqrt{\frac{f_{y}}{100}} \frac{L}{D} ; \frac{\varepsilon_{i}}{\varepsilon_{y}} \geq 7 \\
\frac{f_{i}}{f_{i t}}=\alpha\left(1.1-0.016 \sqrt{\frac{f_{y}}{100}}\right) ; \frac{f_{i}}{f_{y}} \geq 0.2
\end{gathered}
$$

Here, $\sigma_{s c}$ is the actual stress, $\sigma_{t}$ and fit are the stresses in the tension envelope corresponding to $\varepsilon_{s c}$ (current strain) and $\varepsilon_{i}$ (strain at the intermediate point), respectively, $\varepsilon_{y}$ and $E_{s}$ are yielding strain and Young's modulus of the reinforcing bars, $f_{i t}$ and $f_{i}$ are stresses corresponding to $\varepsilon_{i}$ at the tension and compression envelope, respectively.

The buckling length $L$ is related to the spacing of transverse ties, but it may be greater if ties are not stiff enough to provide adequate restraint against buckling. For elements failing by reinforcement buckling, $L / D$ ratios used in the analysis are those experimentally observed over multiple spacing for monotonic tests, while for elements failing due to concrete crushing, $L / D$ corresponding to one transverse spacing was used.

Fig. 8 shows comparison between experimental and numerical results for the compression side. Comparison between response curve with and without taking into account buckling behaviour shows no influence on the compressive strength. However, model with buckling could well simulate the falling branch for configuration 5B and $1 \mathrm{C}$ failing due to reinforcement buckling. As shown experimentally, the load carrying capacity decreases suddenly after reaching the peak and where the onset of reinforcement buckling happened. These observations suggest that buckling of reinforcement should be included for confined end-regions when analysing RC wall, especially when ultimate behaviour and deformations capacity are required.
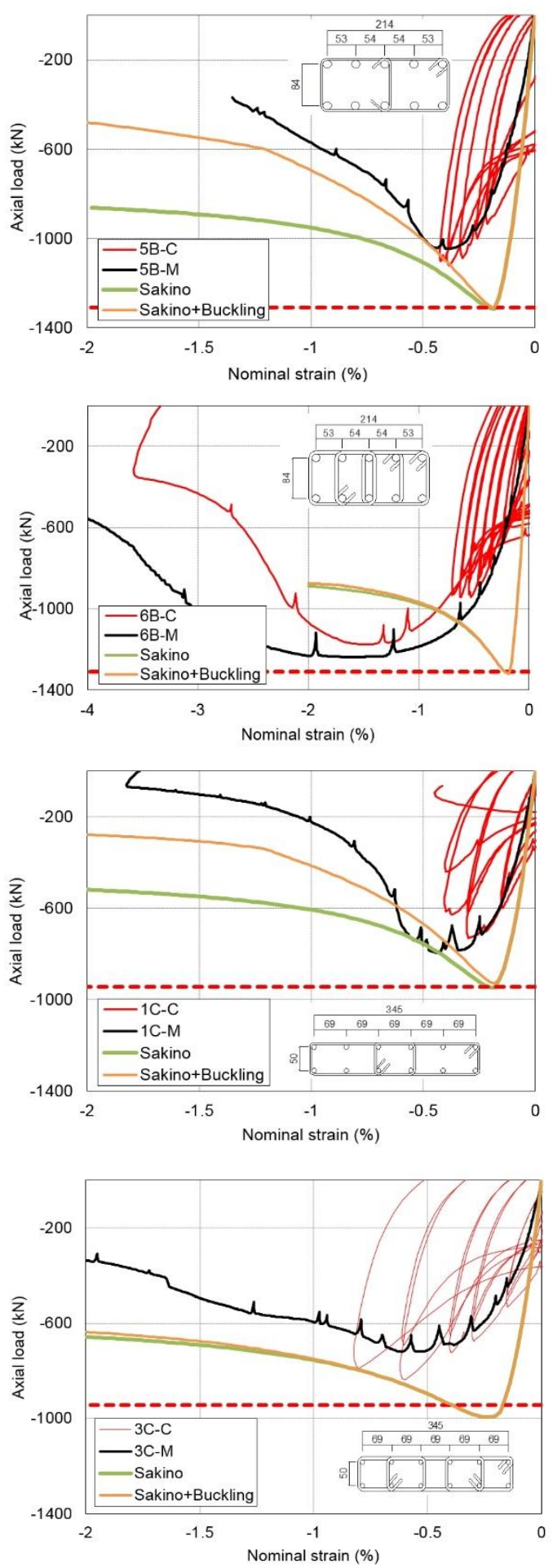

Fig. 8. Axial load-Nominal axial strain relationships.

\section{Conclusions}

An experimental study was conducted on eight $\mathrm{RC}$ rectangular columns that idealize confined boundaries of $\mathrm{RC}$ rectangular walls to examine the effects of slenderness, reinforcement detailing and loading type on their performance. The following conclusions were drawn.

Three different failure modes were observed depending on confinement and slenderness levels: 
crushing of compressive concrete, buckling of longitudinal reinforcement, and global buckling of element. Although load carrying capacity between monotonic and cyclic loadings showed no significant difference, loading type could lead to different final failure modes.

Large transverse reinforcement spacing may result in buckling of longitudinal reinforcement following even limited tensile strain excursions. Intermediate unsupported bars are more susceptible to buckling. Supporting all intermediate bars at the wall confined edge should be considered.

Comparison between monotonic and cyclic response for elements with failure mode governed by buckling of longitudinal reinforcement showed that prior tensile strain reduced considerably the load level at the onset of bars buckling.

Dense transverse reinforcement detailing in thin confined boundaries could not improve their performance. It was also shown that failure due to global buckling is affected by both large axial strain prior to compressive strain and prior crushing of compressive concrete. Imposing a minimum wall thickness would be an alternative means to suppress failures due to global buckling of thin walls.

The project presented in this article was supported by the Ministry of Land, Infrastructure, Transportation and Tourism (Japan).

\section{References}

1. B. Westenenk, J.C. De la Llera, J.J. Besa, R. Jünemann, J. Moehle, C. Lüders, J.A. Inaudi, K.J. Elwood, S.J. Hwang, Response of Reinforced Concrete Buildings in Concepción during the Maule Earthquake, Earthq. Spectra, 28, S1 (2012)

2. J.W. Wallace, L.M. Massone, P. Bonelli, J. Dragovich, R. Lagos, C. Lüders, J. Moehle, Damage and Implications for Seismic Design of RC Structural Wall Buildings, Earthqu. Spectra, 28, S1 (2012)

3. S. Sritharan, K. Beyer, R.S. Henry, Y.H. Chai, M. Kowalsky, D. Bull, Understanding Poor Seismic Performance of Concrete Walls and Design Implications, Earthq. Spectra, 30, 1 (2014)

4. Markeset G, Hillerborg A, Softening of Concrete Compression - Localization and Size Effects, Cement and Concrete Research, 25(4) (1995)

5. K. Takahashi, K. Yoshida, T. Ichinose, Y. Sanada, K. Matsumoto, H. Fukuyama, H. Suwada, Flexural Drift Capacity of Reinforced Concrete Wall with Limited Confinement, ACI Struct. J., 110, 1 (2013)

6. R. Taleb, S. Kono, M. Tani, M. Sakashita, Effects of End Regions Confinement on Seismic Performance of $R C$ Cantilever Walls, $10^{\text {th }}$ U. S. Conference on Earthquake Engineering, Alaska (2014)

7. American Concrete Institute, Building Code Requirements for Structural Concrete (ACI 318-14) and Commentary (ACI318R-14), Farmington Hills, Michigan (2011)
8. P.F. Parra, J.P. Moehle, Lateral Buckling in Reinforced Concrete Walls, $10^{\text {th }} \mathrm{U}$. S. Conference on Earthquake Engineering, Anchorage, Alaska (2014)

9. M.E. Rodriguez, J.C. Botero, J. Villa, Cyclic stressstrain behaviour of reinforcing steel including effect of buckling, J. Struct. Eng-ASCE, 125, 6 (1999)

10. K. Sakino, Y. Sun, Stress-Strain Curve of Concrete Confined by Rectilinear Hoops, J. Struct. Constr. Eng. (Transactions of AIJ), 461, (1994) (in Japanese).

11. R.P. Dhakal, K. Maekawa, Modeling for Postyield Buckling of Reinforcement, J. Struct. Eng-ASCE, 128, 9 (2002)

12. R.P. Dhakal, K. Maekawa, Reinforcement Stability and Fracture of Cover Concrete in Reinforced Concrete Members, J. Struct. Eng-ASCE, 128, 10 (2002) 